\title{
Minireview on Self-Healing Polymers: Versatility, Application, and Prospects
}

\author{
Md. Wasikur Rahman (iD) and Nawrin Rahman Shefa \\ Department of Chemical Engineering, Jashore University of Science and Technology, Jashore 7408, Bangladesh \\ Correspondence should be addressed to Md. Wasikur Rahman; w.rahman@just.edu.bd
}

Received 25 June 2021; Revised 15 August 2021; Accepted 22 August 2021; Published 17 September 2021

Academic Editor: Gyorgy Szekely

Copyright (C) 2021 Md. Wasikur Rahman and Nawrin Rahman Shefa. This is an open access article distributed under the Creative Commons Attribution License, which permits unrestricted use, distribution, and reproduction in any medium, provided the original work is properly cited.

\begin{abstract}
Nature is blessed with self-healing properties. Mimicking nature is a traditional practice to innovate new classes of materials for researchers. In this practice, researchers made a revolutionary approach to innovate self-healing polymer (SHP) that can be used to treat damage-related losses. Different SHPs with various properties have been developed for a wide range of applications. SHPs unlocked the key to the taste of real life through their application and versatility in the sectors close to our day-by-day life of this age and the near future. In this study, we reviewed the scopes and prospects of the application of SHPs owing to different properties. Varieties of amazing properties made SHPs fit in different sectors such as construction, paint and coat, electronics, healthcare, textile, and automotive and aerospace. Similarly, due to having suitable functionality, SHPs can also be used in different industries. Therefore, it is high time to generalize the production of SHPs by suitable research and make sure the easy application for the welfare of human civilization and other living creatures.
\end{abstract}

\section{Introduction}

Self-healing is an innate feature of nature. Nowadays, researchers are concentrating on the development of nature-inspired materials with amazing properties [1]. Selfhealing materials are not part of science fiction anymore. They crossed the boundary between fiction and reality. Selfhealing is such a property that is raising a storm in this field. Its property inspired by nature has been pursued in biomimetic designs and healing systems; the damaged structures are repaired by the strategic transportation of healed materials and the polymerization healing process of the injured area [2]. Healing means filling of discontinuity in materials with other materials that differ from the base materials. In general, the properties of healing materials are dissimilar from the matrix. Mostly, self-healing is aimed at getting again surface continuity of materials with concurrent repairing of significant physical and mechanical properties [3]. Selfhealing polymers are synthetically developed polymers with the aptitude to convert physical energy into chemical/physical or both responses to repair damage autonomously or nonautonomously with external intervention without any human involvement to recover the initial properties, more particularly mechanical properties [4-7].

There is a range of potentials for SHPs. Various natural polymer composites and nanocomposites also show selfhealing behavior $[8,9]$. Cell walls of higher plant bioadhesives develop by using borate to crosslink neighboring protein chains, hyperbranched polyester, and soy polysaccharides [10]; intrinsically, microporous poly(ether-ether-ketone) membranes with a structured surface of natural honeycomb result in improved performance [11]; biologically soft tissue developing processes inspired nanocomposite hydrogel for wound and hemostatic healing [12]; photosynthesis of plants inspired singlet oxygen generation [13] and $\mathrm{CO}_{2}$ fixation by a photocarboxylation process [14]. The generations and classification of SHP are shown in Figure 1. The polymers that provide self-healing features are of two types: (a) intrinsic SHP and (b) extrinsic SHP. Intrinsic SHPs are innate reversibilitybased compounds that can heal the damage by increasing the mobility of polymeric chains temporarily [15]. On the other hand, extrinsic type self-healing is triggered by the incorporation of exogenous agents which then help for self-healing from embedded microcapsules on cracking [16]. Further 


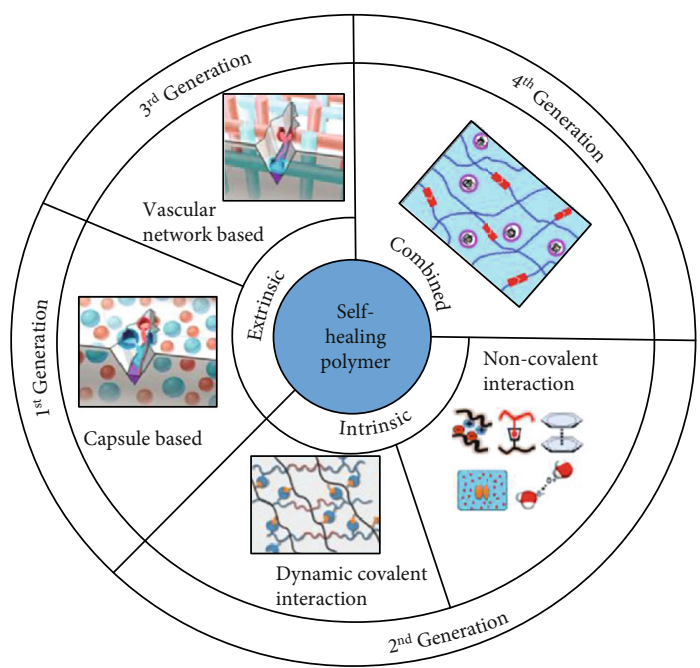

FIgURE 1: Generations and classification of SHPs.

extrinsic self-healing is of two types (i) capsule-based and (ii) vascular-based. In the capsule-based extrinsic SHP, external healing agents are encapsulated in a microcapsule. Cracking causes damage to these microcapsules. Then, healing agents get released to the crack where a polymerizing reaction takes place and the crack got healed. In contrast, vascular-based SHP uses a network of hollow fiber connected into a polymer matrix. These hollow tubes contain healing agents; when they break in the damage position, self-healing occurs. Single-time healing capacity is a major drawback of capsule-based selfhealing. Another big challenge for researchers is dispersing the vascular network which contains healing agents in the polymer-based matrix to fabricate self-healing [17]. On the other hand, the intrinsic type of SHPs is generally developed based on noncovalent bonds or dynamic covalent bonds [18]. Some noncovalent bonds are $\pi-\pi$ stacking, ligand-metal bond, hydrogen bond, or host-guest interaction stacking among other techniques [19-27]. Examples of some covalent interactions are the Diels-Alder reaction, dynamic urea bond, radical exchange, and transesterification, to name a few [27-32].

According to the life cycle and self-healing properties, SHPs can be divided into four generations. $1^{\text {st }}$ generation SHPs are consisting of only a single-cycle capsule-based extrinsic SHP. $2^{\text {nd }}$ generation SHPs came with an intrinsic self-healing mechanism based on reversible chemical bonds to eliminate single-cycle healing problems. However, mechanical and self-healing properties are suppressed. $3^{\text {rd }}$ generation consists of vascular network-based intrinsic healing which showed a way to formulate mechanically stronger SHP. Right now, we are in the fast-growing $4^{\text {th }}$ generation of SHP based on a combined healing mechanism aiming at the elimination of previous limitations [33]. SHPs get updated generation by generation making their bridge to real field of application in the sectors related to both daily commodities and advanced needs. At present, SHPs are receiving a resurrection of interest, as there is a rising demand to integrate molecular level functionality empowering the damage repair capability, impart reprocess ability, or enable extended lifetimes in polymeric materials [34]. In the year
2020, the COVID-19 outbreak stunned the whole world. It freezes the world like a spell. Nevertheless, researchers came forward with even more approaches and continued their research. In 2020, the number of the published article on SHP was the highest according to Google Scholar in recent years as shown in Figure 2. The trend of publications is increasing proportionally over years with 147 publications in 2011, whereas 899 in 2020 . That is enough to understand the level of interest of the researchers and the urgency to take this out of the lab to real field application.

\section{Application of SHPs in Different Sectors}

Investigation on self-healing started in 1970 due to the healing of polymer cracks $[36,37]$. Polymer with self-healing features is newly developed advanced materials with extended lifetimes which can mend themselves when they got damaged without the requirement of detection or repair by manual interference of any kind [38]. The SHP is used to decrease the damage and further chance of material failure along with the long life cycle of polymers and polymer composites [4]. The growth of polymer with self-healing ability is nothing but the advanced modification of the common polymers by incorporating the self-healing features. Application of SHPs covers the field like coatings or paints, sensors, soft robotics, 3D printing, biomaterials, textile, and automobile. Similarly, their potentiality of real-world applications is also analyzed [39].

Now, SHPs are coming out of the lab to real-world applications [8]. It can be used to reduce the cost of maintenance, prolong durability, assure safety, and fabricate advanced materials. In recent years, great emphasis has been given to self-healing materials for real-life engineering approaches [40]. The presence of a material is determined by its functionality in any system. Functionality is a combination of instance properties like electrical and thermal conductivity, color, brightness, adhesion, reflectivity, and hydrophobicity, which are displayed in Table 1. Varieties of SHPs are developing with desired properties to improve functionality for the application in different fields. The enormous versatility of SHPs offers possibilities to apply them in different sectors. The real-world demands, as well as the related implementations, will determine the success of SHPs [34]. Here, we will discuss the application of SHP in different fields with numerous functions.

2.1. Construction Materials. Multiple cycles of self-healing are a matter of concern in the case of the performance of structures made of concrete. Researchers used a mixture of polyvinyl alcohol fibers, steel, superabsorbent polymer, and biochar containing immobilized bacteria to investigate crack healing, recovery of mechanical property, and permeability after multiple cycles of damage. Precipitation of microbial calcite by immobilized bacteria containing biochar combined with a superabsorbent polymer and fiber found superior healing capability for a wider crack surface (>600 $\mu \mathrm{m})$ and microlevel internal cracks comparing autogenous mechanism and concrete mixed with superabsorbent polymer and fiber [55]. 


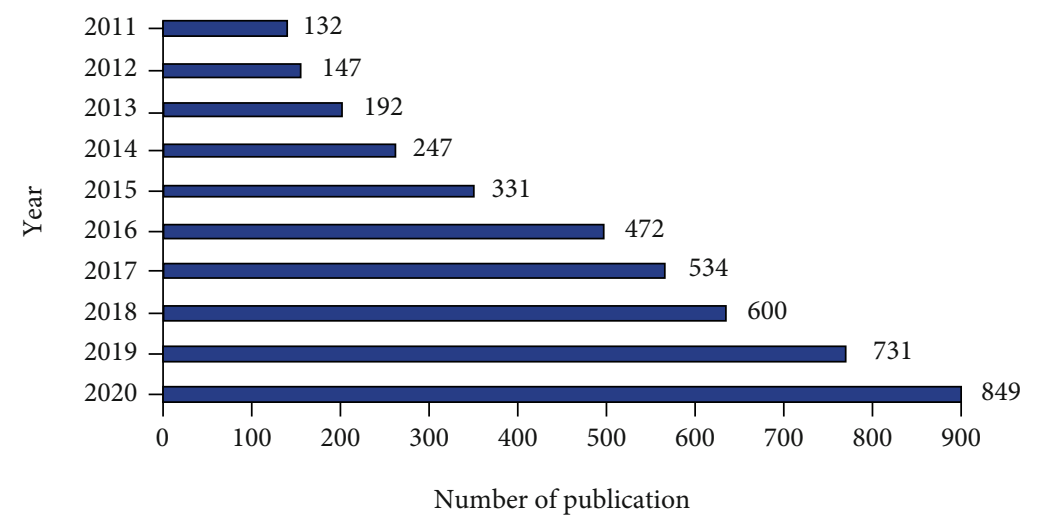

Figure 2: Statistics of the number of publications on SHP in recent years according to Google Scholar (keywords: self-healing polymer, sorted by relevance, date: July 24, 2021) [35].

TABLE 1: Examples of SHPs with different properties.

\begin{tabular}{|c|c|c|c|}
\hline Property & SHPs or composites & $\begin{array}{l}\text { Property introducing or } \\
\text { improving compounds }\end{array}$ & References \\
\hline \multirow{3}{*}{ Electrical conductivity } & $\begin{array}{l}\text { Poly(2-hydroxyethyl methacrylate)+single-walled } \\
\text { carbon nanotubes }\end{array}$ & Single-walled carbon nanotubes & {$[41,42]$} \\
\hline & Glass fiber-epoxy composite+multiwall nanotubes & Multiwall nanotubes & {$[43,44]$} \\
\hline & Ferric ions incorporated polypyrrole-grafted gelatin & Polypyrrole and ferric ions & {$[45]$} \\
\hline \multirow{3}{*}{ Thermal conductivity } & Graphene+thermopolyurethane & Graphene & {$[46]$} \\
\hline & 3D graphene/polydimethylsiloxane composites & $3 \mathrm{D}$ graphene & [47] \\
\hline & Micron boron nitride/thiol-epoxy elastomer composites & Micron boron nitride & {$[48]$} \\
\hline \multirow{3}{*}{ Corrosion resistance } & Superabsorbent polymer microfibers+vinyl-ester polymer (VEP) & $\begin{array}{l}\text { Superabsorbent polymer } \\
\text { microfibers }\end{array}$ & {$[49]$} \\
\hline & Dodecyl amine loaded $\mathrm{TiO}_{2}$ nanotubes dispersed epoxy & Dodecyl amine & {$[50]$} \\
\hline & Cerium nitrate loaded polyaniline nanofibers embedded epoxy ester & $\mathrm{Ce}(\mathrm{III})$ & {$[51]$} \\
\hline \multirow{3}{*}{ Hydrophobicity } & $\begin{array}{c}\text { Carboxylic acid- and fluorine-containing nanocontainers } \\
\text { embedded epoxy }\end{array}$ & Fluorinated groups & {$[52]$} \\
\hline & Multiwall carbon nanotubes/poly(dimethylsiloxane)-polyurea foam & Poly(dimethylsiloxane)-polyurea & [53] \\
\hline & $\begin{array}{c}\text { 3-Mercaptopropyltrimethoxysilane-octavinyloctasilsesquioxane- } \\
\text { 1H,1H,2H,2H-perfluorodecanethiol modified silica (MS) } \\
\text { nanoparticles dispersed polysiloxane latex }\end{array}$ & MS nanoparticles & {$[54]$} \\
\hline
\end{tabular}

In an alternative investigation, the speedy self-sealing can be improved by mixing composites of sulfur polymer combining superabsorbent polymer with Portland cement and calcium sulfoaluminate composed binary cement. The healing capabilities of the superabsorbent polymer as an SHP are very fast, which can heal the damage within 30 mins. The superabsorbent polymer particles taped up and connected the two crack surfaces quickly by swelling up the absorbing water. This self-healing is promoted by nucleation and growing of hydrated yields around the nucleus. A better rapid self-healing increased proportionally with an increasing calcium sulfoaluminate ratio [56].

Polymer-cement composites were formulated by mixing poly(ethylene-co-acrylic acid) zinc salt powder, bisphenol A diglycidyl ether (BPA), two base cement $\mathrm{H}$, and thermal shock-resistant cement (TSRC). Polymer-cement composites maintained their self-healing property for thirty days at $300^{\circ} \mathrm{C}$. These cement composite materials showed a com- pressive strength of more than 1000 psi after a day, just as the requirement of wellbore applications. These advanced polymer-cement composites are mechanically stable, ductile, and self-healable. It is expected that conventional wellbore cement could be replaced by polymer cement which can be applied for the extraction of geothermal and fossil energy [57].

2.2. Paint and Coat. The addition of epoxy resins to a painting enhances the colors and gives the piece a glossy, clean finish. The development of epoxy resin systems which are mechanically tough yet easily healable and recyclable is highly desirable but remains considerably difficult. These innovative epoxy resins based on plant oils were successfully produced using dithiol modified boronic ester and completely epoxidized plant oils by a "thiol-epoxy" click reaction that is thermally triggered. The maximum tensile strength of the plant oil-based epoxy resins was $43.2 \mathrm{MPa}$, and the maximum was $25 \%$ elongation at break. At normal 
temperature, the self-healing effectiveness of vegetable oilbased epoxy resins might be $90 \%$ in a day. Furthermore, even after 9 rounds of reprocessing, the mechanical qualities of resins that have been recycled remained at $80 \%$ of those of the original resins [58]. These recent developments of epoxy resin-based SHPs with desired toughness added a new height to the potential of using SHPs even for critical engineering construction material.

By combining an epidermis-like hierarchical multiplelayered structure with mechanically stable graphene oxide, the fundamental dilemma of achieving stiffness with selfhealing can be overcome. This type of smartly ordered system of coating can provide long-term stability with an effective healing ability. Among all self-healing polymeric films, it has the greatest stiffness $(31.4 \pm 1.8 \mathrm{GPa})$ and hardness $(2.27 \pm 0.09 \mathrm{GPa})$, which is similar to the enamel of the tooth. This hybrid layer-by-layer assemble technique was demonstrated by depositing a thin quasilinear layer-by-layer (l-LBL) film with graphene oxide (GO) nanosheets as 2D fillers on top of a thick exponential layer-by-layer (e-LBL) counterpart to imitate the hierarchical stratified structure of the epidermis (Figure 3). The exponential layer-by-layer part is generally made of poly(vinyl alcohol)/tannic acid [59].

Epoxy monomer as a self-healing agent and dodecyl amine as a corrosion inhibiting agent is enclosed in a single coated layer providing self-directed corrosion inhibition which helps to develop a smart coating around the metal. Titania $\left(\mathrm{TiO}_{2}\right)$ nanotubes with an average size of $0.02 \mu \mathrm{m}$ were impregnated with dodecylamine and epoxy monomer where titania nanotubes interspersed into the epoxy matrix that can be applied on steel. The damaged area was nearly healed within $96 \mathrm{hrs}$, and the reduction in the corrosion rate is observed for epoxy and healing additives-coated steel even after emerging in saline water after 5 days [50]. Microcapsules responsive to UV dispersed coating are formulated for repairing damage in space. UV-responsive microcapsules are made by UVtriggered polymerization of Pickering emulsions and then embedded in silicon resin matrices. The inner polymeric shell of microcapsules is quickly degraded by the outer pure $\mathrm{TiO}_{2}$ shell under UV radiation. Due to the dual release method, UV-responsive microcapsules can discharge more agents even more effectively than commonly employed damage healing systems. Furthermore, the harmful effects of UV radiation in space can be transformed into beneficial ones using this UVresponsive microcapsule. This property makes the material suitable for use in aerospace coatings. Additionally, in a very recent study, researchers described a strategy for creating a strong and low-temperature mendable supramolecular system of polypropylene glycol- (PPG-) polydimethylsiloxane(PDMS-) Zn by integrating both high dynamic crosslink bonds and low crosslink density into polyurea networks. The resulting PPG-PDMS-Zn-0.5 polymer showed $0.98 \mathrm{MPa}$ tensile strength and showed $97 \%$ self-healing efficiency at $-20^{\circ} \mathrm{C}$. This type of supramolecular polymers with unique features can also be applied in Antarctic pole exploration antifrosting and anti-icing paints [48].

2.3. Sensors, Electrical, and Electronics. A conductive hydrogel with self-healing ability and excellent biocompatibility

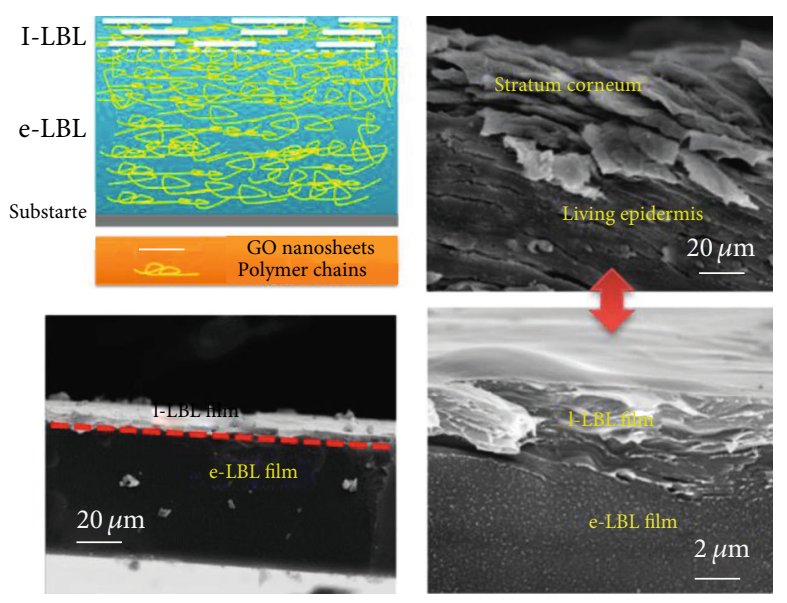

Figure 3: Hybrid layer-by-layer films simulating the structure of the epidermis: (a) schematic representation of the polymer composite and layout of hybrid LBL films, (b) the SEM image showing the epidermis skin taken from the finger, (c) the SEM image showing the thickness of different layers of hybrid films, and (d) the enlarged SEM image showing quasilinear layer-bylayer (l-LBL) film on exponential layer-by-layer which is structurally similar to the epidermis as shown in (b) [59].

was prepared based on polypyrrole, oxidized sodium alginate, and aminated gelatin as reported in 2019 (Figure 4). The cracked hydrogel shows self-healing capabilities within 40 min due to its reversible Schiff base structure. The hydrogel was shown to work as healable wires to reconnect disconnected circuits or as a single circuit component to light LED bulbs. Furthermore, polypyrrole hydrogel can be used in mechanical sensors because of its adjustable resistance and good flexibility under compression and bending motion. Therefore, it can be potential material in biocompatible soft electronics devices [60]. The first self-powered, self-healable, and wearable ultraviolet photodetector was made based on agarose/poly(vinyl alcohol) double-network hydrogels which are mechanically strong and can heal multiple cycle damages. The photodetector can restore $90 \%$ of primary skills after five healing cycles with the addition of a doublenetwork hydrogel substrate, and each rapid healing time is reduced to only 10 seconds [61]. It can expand the scope of soft robotics and prosthetics with sensors.

Additionally, a highly water-unresponsive self-healing elastomer is polybutadiene-based poly(urea-urethane) (PBPUU) which is highly stretchable (1100\%) and mechanically strong $(\approx 6.5 \mathrm{MPa})$. Without support from an external source, this elastomer shows great self-healing efficiency (>80\% after $\approx 1$ day) in a wet environment (e.g., underwater). The polymer's self-healing efficiency is also good enough for surface scratches in the air. Furthermore, when it functioned in salty seawater or an extremely wet environment, the healing competence directs to the rejection due to the damages in the structure [62]. It is reported that an electronic skin (e-skin) made of PBPUU and nanostructured conductive fillers has an excellent performance in various $\mathrm{pH}$, temperature, and pressure sensing in both atmospheric and underwater conditions. Similarly, silver nanowire-based electrodes were used in the multilayered e-skin (Figure 5) 


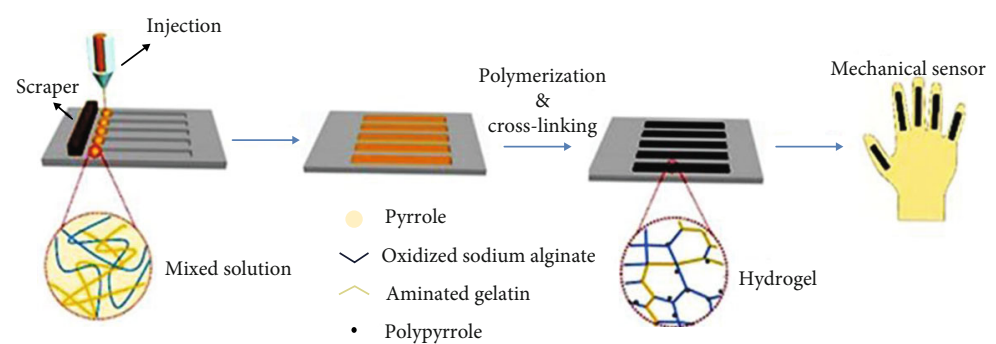

FIGURE 4: Schematic representation of hydrogel-based mechanical sensor preparation process [60].

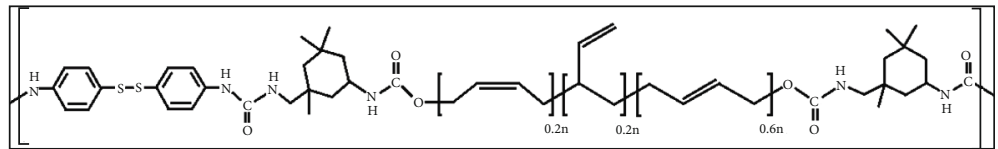

Figure 5: Chemical structure of PBPUU [63].

to extend the heater's connection to the edge. Damage detecting neuron-like complex structure was created using a nanostructured network of conductive carbon black dispersed in the PBPUU for determining and mapping local damage. The sensing layer was made of single-walled carbon nanotubes. The repair process led to the healing of a superficial crack that can be achieved in 30 seconds rather than $24 \mathrm{hrs}$. On the other hand, healing of extensive damage required $5 \mathrm{~min}$ [63].

A new type of self-healing microcapsule has been developed using aqueous conductive core materials that are lowcost, nontoxic, and nonpolluting. An in situ polymerization process was used to create these microcapsules with a melamine-formaldehyde resin shell and an aqueous solution core. During the long-term operation of the gadget, it is beneficial to minimize the temperature of the circuit itself. Furthermore, these microcapsules are capable of withstanding pressures of up to $14 \mathrm{~N}$. These microcapsules had an electrical conductivity of $6.232 \mathrm{~ms} \mathrm{~cm}^{-1}$. We believe that these selfhealing microcapsules will have a great variety of applications in the long-term development of electronics [64].

2.4. Healthcare. Researchers developed thermosensitive and SHP network hydrogel based on polyacrylamide/gelatin (PG) hydrogel which has a match with native vocal fold tissue both physically and functionally as shown in Figure 6 . The PG hydrogel has a minimum reaction with the foreign body when implanted. It also creates strong resistance in a dehydrated environment and lasts for 40 days maintaining $60 \%$ humidity. PG hydrogel showed strong adhesion when attached with tissues of the vocal fold. The synthetic vocal fold tissue of PG hydrogel named ex vivo canine can be implanted for the recovery of the function [65].

Based on the Biginelli reaction, a self-healing hydrogel with antioxidant characteristics has been prepared to contain monomer phenylboronic acid (PBA) and 3,4-dihydropyrimidin-2(1H)-one (DHPM) groups. Radical polymerization of monomer PBA-DHPM with poly(ethylene glycol methyl ether) methacrylate produced a water-soluble copolymer. The copolymer is rapidly crosslinked with poly(vinyl alcohol) by borate ester bonds generating a hydrogel with self-healing, noncytotoxic, and antioxidant properties. The implant ability of this hydrogel has been tested by injecting the hydrogel under the skin of a mouse model which did not show any augmentative reaction [66]. Similarly, an injectable self-healing adhesive is made up by interacting polyphenol compound tannic acid with eight-arm poly(ethylene glycol), and end-capping occurred with succinimide glutarate active ester. The poly(ethylene glycol)/tannic acid adhesive can repetitively attach stiffly with porcine tissues. It can also be used for closing the coronary artery under a huge incision tension and can tolerate a load of up to $2 \mathrm{~kg}$. Due to the special features like instant self-healing, antiswelling, shear-thinning, injectability, and strong long-lasting adhesion to effortless outstanding healing effects, poly(ethylene glycol)/tannic acid adhesive may offer an alternative for conventional surgical treatment methods [66].

Besides, poly(vinyl alcohol)-based self-healing hydrogels have a significant effect on healthcare functionalities. In fact, wound healing dressing is desired to be compatible with the skin, endowing good therapeutic properties and enough strength to protect the wounded area safe from the outside environment. Recently, salep/poly(vinyl alcohol)-based ultratough double-network hydrogel has been developed. $\mathrm{H}$-bonds and azomethine crosslinking between oxidized and ethylene diamine-modified salep chains attain selfhealing. The resulting hydrogel has great mechanical properties with a maximum of $14 \mathrm{kPa}$ Young's modulus, $90 \mathrm{~kJ} \mathrm{~m}^{-3}$ fracture energy, $400 \mathrm{kPa}$ compressive stress, $48 \mathrm{~N} \mathrm{~m}^{-1}$ adhesive strength, and A375 cells having viability of over $80 \%$ making it ideal for therapeutic purposes. The macroscopic evaluation demonstrated that fusing the two networks into a single system in green medium Arnebia extract and silver nanoparticles combined resulted in $100 \%$ healing in 21 days [67].

2.5. Textile. A polyester fabric coated with crosslinkable polymer consisted of both hydrophilic and oleophilic functional groups having special features. To prepare coating solution, glycerol propoxylate triglycidyl ether was mixed 


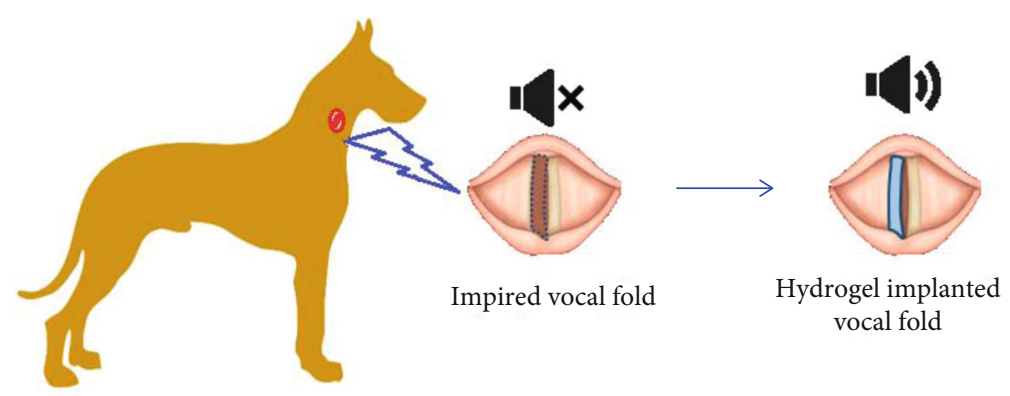

Figure 6: Implantation of PG hydrogel as an artificial vocal fold tissue [60].

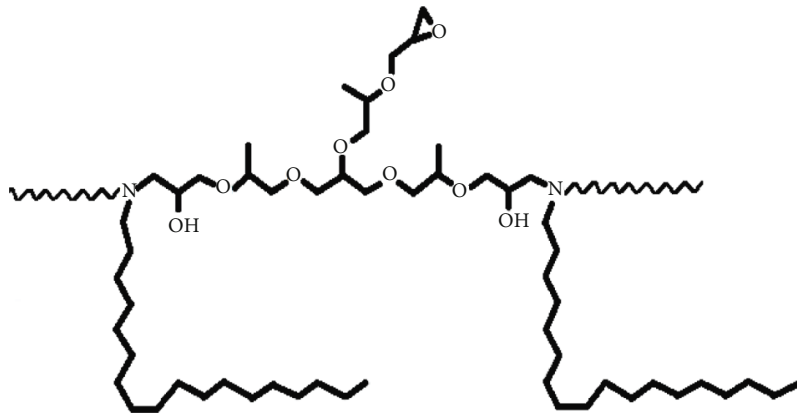

(a)

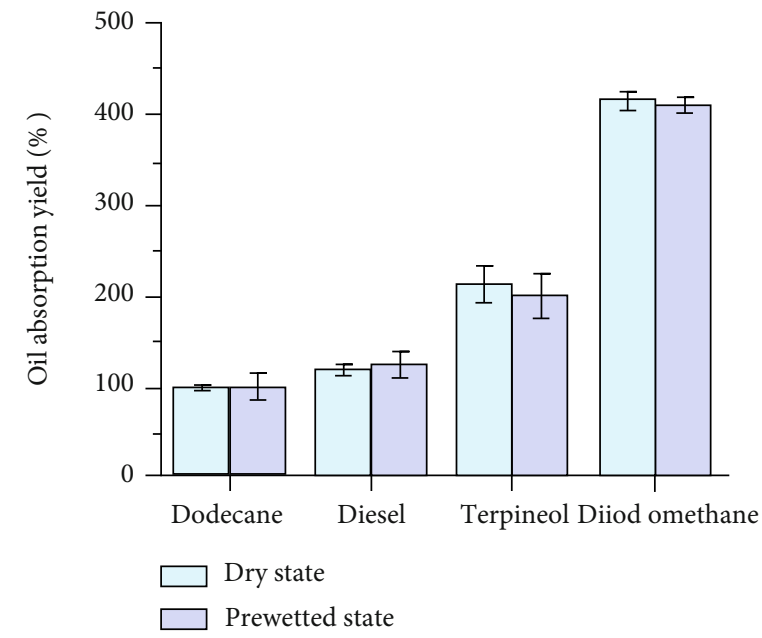

(b)

FIGURE 7: (a) Chemical structure of glycerol propoxylatetriglycidyl ether-octadecylamine; (b) oil absorption yield of the dry and prewetted glycerol propoxylatetriglycidyl ether-octadecylamine-coated fabrics [68].

with octadecylamine in ethanol through epoxide-amino coupling reaction. The solution becomes translucent after the completion of the reaction. After treatment with crosslinked polymer, the fabric exhibited a contact angle of $0^{\circ}$ for water. Therefore, water adsorbed completely into the fabric within 1 second. The oil absorption yield of the dry and prewetted fabrics is shown in Figure 7. In addition, the oil fluids have the potential to spread fully to the water-wetted fabric within 60 seconds. The most interesting matter is superoleophilicity underwater. It is also self-healable and chemical damageresistant. The high moisture resistance caused oil recovery very steady. Such rare superamphiphilicity prospects innovative features to apply in diverse fields [68].

The use of SHP on various textile products enhances the efficiency and efficacy of textile goods. Similarly, the use of methyl vinyl silicon rubber with inorganic silsesquioxane on rubber gloves increases the life span of the gloves. To understand the effect of textile reinforcement, three unwoven fabrics of different raw materials and the same structure (polyamide, cotton-polyamide, and cotton) were taken, and it was found that the fabric treated with textile reinforcement shows higher stability. It has also been tested that the composites of methyl vinyl silicon rubber and silsesquioxanes can be upgraded with the addition of textile reinforcement, and these types of composites provide good chemical permeation resis- tance that makes this material suitable for use in barrier protection [69]. For the preparation of a self-healing electromagnetic interference shielding fabric, carbon nanotubepoly(2-hydroxyethyl methacrylate) is aligned on a nonwoven fabric with magnetic field electrospinning and cross-stacking fabric layers that are aligned as shown in Figure 8. Because of the materials' unique aligned carbon nanotube stacking and porous structure, they can successfully absorb electromagnetic interference even at extremely low carbon nanotube loading levels (0.17 weight percent). Additionally, the hostguest interaction between $\beta$-cyclodextrin and the adamantane moieties not only caused the fabric to automatically stick together but also caused it to self-heal scratches in 100 percent humidity. The electromagnetic interference shielding property reclaimed up to $90.86 \pm 3.90 \%$ after healing [70].

2.6. Automotive and Aerospace. At the nanoscale level, conductivity mapping is achieved by a multifunctional newly developed fire retardant graphene/polyhedral oligomeric silsesquioxane epoxy resin via tunneling atomic force microscopy which can measure ultralow currents starting from $80 \mathrm{fA}$ to $120 \mathrm{pA}$. This fire retardant graphene/polyhedral oligomeric silsesquioxane epoxy resin composite can be used in the aeronautic and aerospace sectors. The mechanical performance, thermal stability, electrical conduction, and fire 


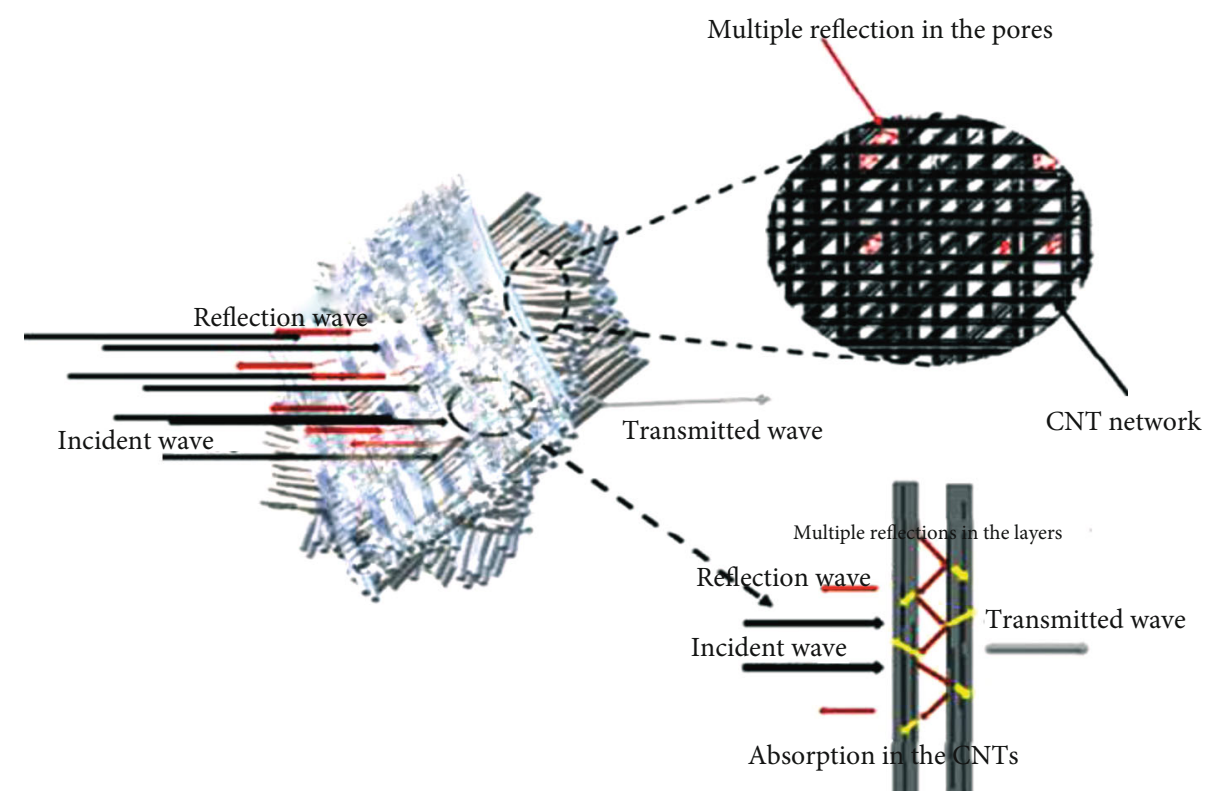

FIGURE 8: Schematic diagram of electromagnetic interference shielding on porous nonwoven fabric [70].

resistance of graphene/polyhedral oligomeric silsesquioxane epoxy resin have been verified to understand the properties of this material [71]. A UV-responsive microcapsule-based system can be used for damage healing of spacecraft coatings [72]. Similarly, AA7475 is a high-strength alloy with selfhealing properties generally used in the aerospace industry. Additionally, biobased polyurethane coatings are derived from vegetable oils with and without the integration of zinc microsize flakes as a corrosion inhibitor. Zinc-containing coatings deliver effective corrosion inhibition in AA7475, and it has been observed that the inhibiting capability of AA7475 notably got better with the amount of 7.5 weight $\%$ zinc microflakes in the coating [73].

Long-lasting tires and reduction of fuel consumption without sacrificing safety are a demand of the automobile industry. A self-healing tire was developed by styrenebutadiene rubber matrix and reclaimed tire waste as the sustainable filler. Furthermore, the addition of ground tire rubber to the matrix got better concurrently the rolling resistance, wet grip, and mending ability. In a recent study, the researcher found that styrene-butadiene rubber and "styrene-butadiene rubber/ground tire rubber" showed a $100 \%$ regaining of stiffness and relaxation dynamics as a result of cyclic deformation, leading to the formation of a heterogeneous rubber network. The magic triangle (Figure 9) of the tire can be overcome with these new materials [74].

2.7. Miscellaneous. Researchers reported that polymers of light molecular weight crosslinked together through dense hydrogen bonds which make them robust and self-healable, despite their very slow diffusion dynamics. The incorporation of thiourea in the crosslink is an important point because it irregularly forms a zigzag hydrogen-bonded arrangement that does not induce unwanted crystallization. The incorporation of a structural element for triggering the exchange of pairs of hydrogen bonds empowers the cracked

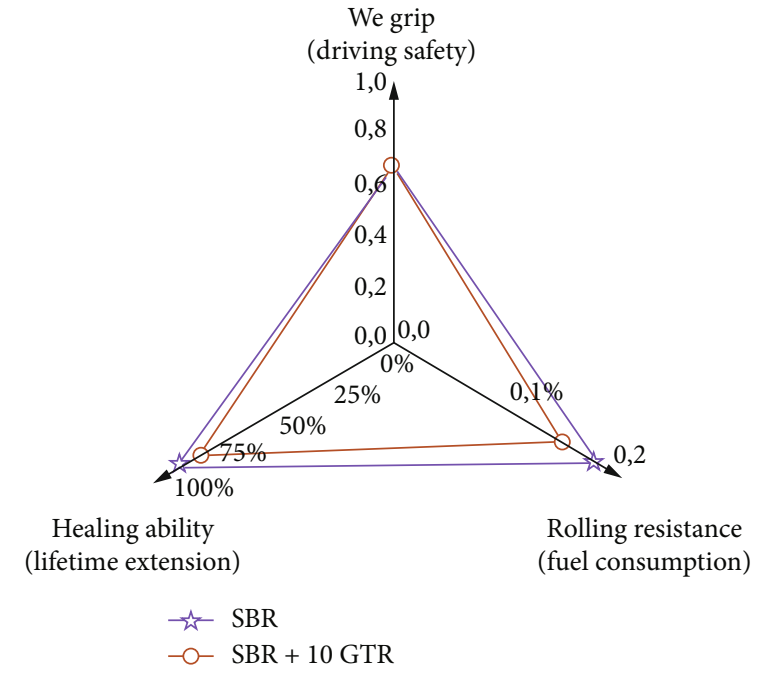

FIgURE 9: Magic triangle (healing ability, wet grip, and rolling resistance) of SBR and SBR/10GTR compounds [74].

portions to unite by compression [75]. Additionally, selfhealable glass can be a potential material for cellphone screens and other delicate devices [76]. A molecularly designed photopolymerization-based additive was manufactured with self-healable elastomeric structures as reported in 2019. This photoelastomer 3D-printable ink incorporates both thiol and disulfide groups. At first, the thiol group reacts with photoplastomer to form thiol-ene photopolymerization, and then, disulfide metathesis reaction takes place which enables the self-healing properties. Projecting microstereolithography systems, researchers established rapid additive manufacturing techniques to produce selfhealable structures with single or multimaterial. This selfhealable structure can be used to produce multiphase composites, 3D soft actuators, and architectured electronics. The 3D actuator was designed and additively manufactured 


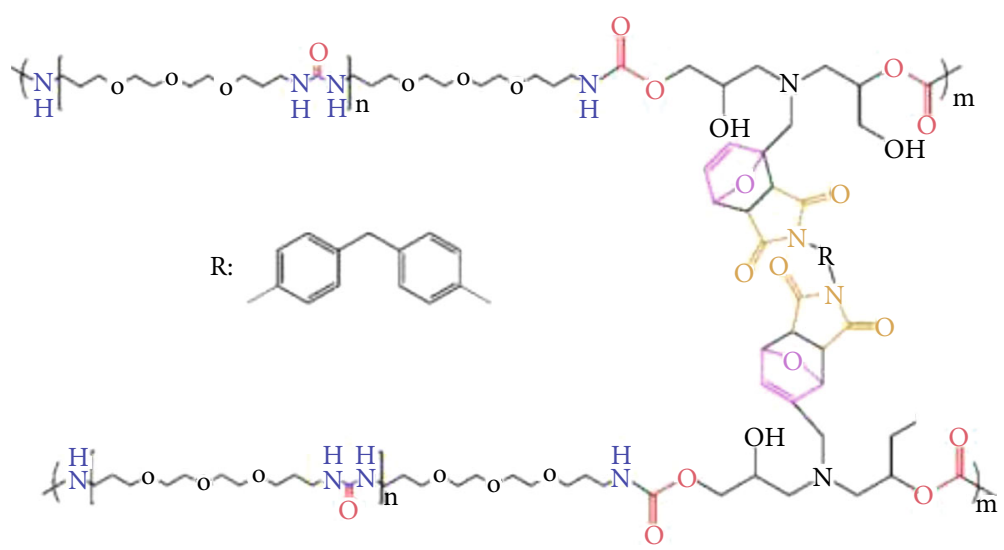

FIgURE 10: Chemical structure of polyurethane-urea Diels-Alder adduct (PUUa-DA) [79].

which was a nacre-like stiff-soft composite and able to lift a weight ten times of its weight. The actuator can reestablish the toughness to over $90 \%$ after rupture [77].

Due to the synergistic environmental stability of the polyimide membrane and polydimethylsiloxane/octadecylamine coating, a simple method for fabricating polyimide nanofibrous membranes with self-healing superhydrophobicity, remarkable separation efficiency towards a range of oil/water mixtures and water-in-oil emulsions, and desirable adaptability in harsh environments is developed. Because of these characteristics, the membrane is a prospective separation material for effective oil/water separation in a real-world setting [78].

Green chemistry is also practiced in the field of SHPs by developing green routes to synthesis and environmentfriendly SHPs. Using $\mathrm{CO}_{2}$ as a nontoxic and furfuryl amine as a renewable feedstock, a green method to synthesize biobased nonisocyanate polyurethane-urea Diels-Alder adduct (PUUa-DA) was reported (Figure 10) [79]. The crosslinked PUUa-DA had tensile stress of $18.5 \mathrm{MPa}$, a modulus of $151 \mathrm{MPa}$, and a $136 \%$ elongation at break. The self-healing response is provided by dynamic Diels-Alder bonds and $\mathrm{H}$-bonds, which contribute to a 94 percent recovery in tensile strength after heating [79].

A composite of polymethacrylamide and carbon mimics the photosynthesis of plants, and carbon fixation from the atmosphere allows its growing, strengthening, and selfrepairing. The substance utilized by the researchers, a gel matrix formed of an aminopropyl methacrylamide and glucose polymer, an enzyme called glucose oxidase, and chloroplasts becomes tougher as the carbon is incorporated. Under ambient $\mathrm{CO}_{2}$ and light for $18 \mathrm{hrs}$, this system reaches a growth rate of $60 \mathrm{~m}^{3} \mathrm{~h}^{-1}$ per chloroplast, thickening with a $3 \mathrm{kPa}$ shear modulus. This polymer might be utilized in building, repair, or protective coatings in the future turning greenhouse gases into a carbon-based compound that self-reinforces [29].

\section{Prospects}

There are various sectors where SHP is now being used, for instance, self-healing coating of LG flex 2 cellphones, selfhealing asphalt of Heijmans, scratch shield paint of Nissan, self-healing paint for airplanes of KLM-Air France, puncture SHPs for targets, and aerospace [80]. This is indicating that SHP not only is technology confined in the lab but also has wider practical applications. This technology has stepped out of the lab and is getting ready to jump into our daily life. The market size of the international self-healing materials was valued at USD 291.4 million in 2018, and it has been expected that the rising compound annual growth rate (CAGR) will be $46.1 \%$ in the time range of 2019 to 2025 . The growth rate of the market size of the self-healing materials in the United States is shown in Figure 11. The driving factors of the rising market size of smart SHPs are the application of these materials in various industries and mending capabilities of damage caused by mechanical stress. Due to the escalation of demand for advanced and highly strong materials to enhance productivity and to reduce losses because of the damage of instruments, people are more likely to use SHP composites. Mainly automobile and electronic industries are tending to this type of composite materials. Additionally, the increasing application of SHPs in the paint and coating industry indicates the future demand in various industries [81].

A patent has been published from Apple by the US Patent and Trademark Office related to the application of SHP in a folding iDevice in January 2020. In that patent, they describe that they include a layer of SHP on the display of that device. The display cover layer may comprise a layer of elastomer to increase flexibility. Self-healing may be triggered by external application light, heat, electrical current, or other types of external incentives. While using an electronic device, the display screen can get scratched, but the application of SHP may fill the damage. A partnership between MIT and Lamborghini resulted in a stunning hypercar concept for the future self-healing electric sports car. The TerzoMillenio is a prototype car for a thirdmillennium vehicle. It is exceptionally capable of delivering high peak power along with regenerating kinetic energy by ensuring electric power release and generation [82]. Human limbs are designed with a critical layer-by-layer structure where soft tissue is attached to the rigid bone. Therefore, it is nearly impossible to construct human limbs artificially, and it is a big challenge for the scientist to develop a suitable 


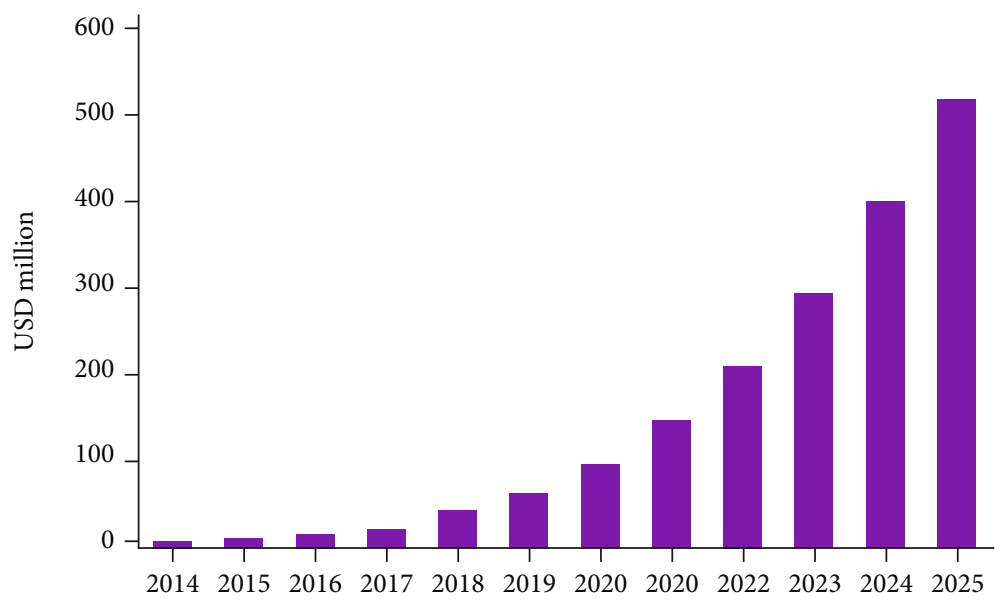

FIGURE 11: Market size of self-healing materials in the United States according to product 2014-2025 [81].

technology for the production of human body parts [83]. Accepting that challenge, researchers have developed a technology that can produce a $3 \mathrm{D}$ printable new type of SHP combining furan and maleimide, and they believe that this new material can help in the production of more realistic human prosthetics [84]. Additionally, the self-healing asphalt can be used in the construction of a road with longer service life. Therefore, conventional asphalt can be replaced with this newly developed material. This material can repair damage (through a hybrid input-output system) caused by natural disasters or road accidents. They concluded that self-healable roads may decrease emissions by 16 percent and decrease costs by 32 percent compared with a conventional road over the service life [85].

Overall, the future of SHP depends on the ability to expand the service life of products, survivability in critical conditions, being economic, and ecological compatibility. Optimization of mechanical properties of building materials along with self-healing property can be used to build important structures due to having a long service life of SHP. Concealed faults are one of the key problems endangering the long-term stability of mechanically strong polymers which are widely used engineering materials. An SHP created by curing a readily available commercial epoxy monomer with a synthetic dynamic crosslinker may mend internal flaws completely numerous times while sustaining mechanically tough polymers' structural stability during healing. This method has a lot of promise for industrial uses [86].

SHPs can be a solution to the problems in repairing damages such as flying aircraft, deep-water pipelines, underground structures, and machinery in high thermal conditions. The brand new technology of multilayer SHPs equipped with multisensor circuits can lighten up soft robotics and lead prosthetic organs with sense. Even SHPs with flexibility, nontoxicity, and biocompatibility can play a great role in developing artificial organs too. SHPs of such kind can also be used to develop smart fast healing wound dressing for critical wound management where regular wound dressings struggle or are unable to manage. Using SHP membranes can make filtration methods more effi- cient by making the process more continuous due to less maintenance. The new run of SHP along with the green chemistry is not only with biocompatible self-healing polymeric materials but also with the green route of synthesis giving a rise to our expectations to SHP for gifting a pollution-free future.

\section{Conclusion}

Considering the long-term stability, self-heal ability, and flexible nature, SHPs are the best composite material among the next-generation materials. This material can be used in many diverse environments with higher stability comparing conventional material. Therefore, using this composite material would be economic in industrial sectors. The progress of SHPs day by day makes this type of material worth using in every sector. The special features of newly developed SHPs reveal a new way to produce and apply advanced materials. Now, these new types of material enable us to produce various products with a longer lifetime and stability. The experiments to develop new SHPs and experiments on SHP composites incorporating different elements or compounds should be continued to get the best to apply in every sector and obtain more versatility of SHPs. Ensuring the availability of SHPs is a must to apply on large scale. This will not be possible through critical and expensive synthesis methods. Developing synthesis methods that are less critical, greener, and cost-friendly needs more attention from the researchers. The green synthesis route is important because we should not mess with nature, stay with it, and observe the pathways of nature more closely to get inspiration for developing amazing SHPs. At present, products are successfully being used in different sectors containing SHP. Although the development of SHPs has done much through advanced research, there is a lot of progressive research still to be done to take the SHPs in practical and industrial applications. Approaches to the industrial application of SHPs just have started, and it is time to fasten the seat belt and start the journey to the era of SHPs. 


\section{Conflicts of Interest}

The authors declare no conflicts of interests.

\section{Acknowledgments}

This work acknowledges the technical support of MENTECH Labs of Jashore University of Science and Technology, Bangladesh.

\section{References}

[1] R. S. Trask, H. R. Williams, and I. P. Bond, "Self-healing polymer composites: mimicking nature to enhance performance," Bioinspiration \& Biomimetics, vol. 2, no. 1, pp. P1-P9, 2007.

[2] M. W. Lee, "Prospects and future directions of self-healing fiber-reinforced composite materials," Polymers, vol. 12, no. 2, p. 379, 2020.

[3] N. N. Sitnikov, I. A. Khabibullina, V. I. Mashchenko, and R. N. Rizakhanov, "prospects of application of self-healing materials and technologies based on them," Inorganic Materials: Applied Research, vol. 9, no. 5, pp. 785-793, 2018.

[4] J. Kumar Banshiwal and D. Nath Tripathi, "Self-healing polymer composites for structural application," in Functional Materials, IntechOpen, 2019.

[5] Y. Takashima and A. Harada, Encyclopedia of Polymeric Nanomaterials, Springer, 2020.

[6] I. L. Hia, V. Vahedi, and P. Pasbakhsh, "Self-healing polymer composites: prospects, challenges, and applications," Polymer Reviews, vol. 56, no. 2, pp. 225-261, 2016.

[7] J. Kötteritzsch, U. S. Schubert, and M. D. Hager, "Triggered and self-healing systems using nanostructured materials," Nanotechnology Reviews, vol. 2, no. 6, pp. 699-723, 2013.

[8] C. I. Idumah, "Recent advancements in self-healing polymers, polymer blends, and nanocomposites," Polymers and Polymer Composites, vol. 29, no. 4, pp. 246-258, 2021.

[9] S. B. Jagtap, V. D. Patil, K. Suresh et al., "Functionalized carbon nanotube reinforced polymer nanocomposite microcapsules with enhanced stiffness," Colloids and Surfaces A: Physicochemical and Engineering Aspects, vol. 550, pp. 82-89, 2018.

[10] W. Gu, F. Li, X. Liu et al., "Borate chemistry inspired by cell walls converts soy protein into high-strength, antibacterial, flame-retardant adhesive," Green Chemistry, vol. 22, no. 4, pp. 1319-1328, 2020.

[11] M. A. Abdulhamid, S. H. Park, Z. Zhou, D. A. Ladner, and G. Szekely, "Surface engineering of intrinsically microporous poly(ether-ether-ketone) membranes: from flat to honeycomb structures," Journal of Membrane Science, vol. 621, p. 118997, 2020.

[12] S. K. Das, T. Parandhaman, and M. D. Dey, "Biomoleculeassisted synthesis of biomimetic nanocomposite hydrogel for hemostatic and wound healing applications," Green Chemistry, vol. 23, no. 2, pp. 629-669, 2020.

[13] W. Schilling, Y. Zhang, P. K. Sahoo et al., "Nature inspired singlet oxygen generation to access $\alpha$-amino carbonyl compoundsvia1,2-acyl migration," Green Chemistry, vol. 23, no. 1, pp. 379-387, 2020.

[14] X. He, L. Q. Qiu, W. J. Wang, K. H. Chen, and L. N. He, "Photocarboxylation with $\mathrm{CO}_{2}$ : an appealing and sustainable strategy for $\mathrm{CO}_{2}$ fixation," Green Chemistry, vol. 22, no. 21, pp. 7301-7320, 2020.
[15] W. H. Binder, Ed., Self-Healing Polymers: From Principles to Applications, John Wiley \& Sons, 2013.

[16] S. An, M. W. Lee, A. L. Yarin, and S. S. Yoon, “A review on corrosion-protective extrinsic self-healing: Comparison of microcapsule-based systems and those based on core-shell vascular networks," Chemical Engineering Journal, vol. 344, pp. 206-220, 2018.

[17] N. I. Khan, S. Halder, S. B. Gunjan, and T. Prasad, "A review on Diels-Alder based self-healing polymer composites," IOP Conference Series: Materials Science and Engineering, vol. 377, p. 012007, 2018.

[18] Y. Bai, Y. Chen, Q. Wang, and T. Wang, "Poly(vinyl butyral) based polymer networks with dual-responsive shape memory and self-healing properties," Journal of Materials Chemistry A, vol. 2, no. 24, pp. 9169-9177, 2014.

[19] M. Burnworth, L. Tang, J. R. Kumpfer et al., "Optically healable supramolecular polymers,” Nature, vol. 472, no. 7343, pp. 334-337, 2011.

[20] S. Coulibaly, A. Roulin, S. Balog et al., "Reinforcement of optically healable supramolecular polymers with cellulose nanocrystals," Macromolecules, vol. 47, no. 1, pp. 152-160, 2014.

[21] K. Haraguchi, K. Uyama, and H. Tanimoto, "Self-healing in nanocomposite hydrogels," Macromolecular Rapid Communications, vol. 32, no. 16, pp. 1253-1258, 2011.

[22] A. Phadke, C. Zhang, B. Arman et al., "Rapid self-healing hydrogels," Proceedings of the National Academy of Sciences of the United States of America, vol. 109, no. 12, pp. 43834388, 2012.

[23] T. Kakuta, Y. Takashima, M. Nakahata, M. Otsubo, H. Yamaguchi, and A. Harada, "Preorganized Hydrogel: selfhealing properties of supramolecular hydrogels formed by polymerization of Host-Guest-Monomers that contain cyclodextrins and hydrophobic guest groups," Advanced Materials, vol. 25, no. 20, pp. 2849-2853, 2013.

[24] M. Zhang, D. Xu, X. Yan et al., "Self-healing supramolecular gels formed by crown ether based Host-Guest interactions," Angewandte Chemie International Edition, vol. 51, no. 28, pp. 7011-7015, 2012.

[25] J. Fox, J. J. Wie, B. W. Greenland et al., "High-strength, healable, supramolecular polymer nanocomposites," Journal of the American Chemical Society, vol. 134, no. 11, pp. 53625368, 2012.

[26] M. V. Biyani, E. J. Foster, and C. Weder, "Light-healable supramolecular nanocomposites based on Modified cellulose nanocrystals," ACS Macro Letters, vol. 2, no. 3, pp. 236-240, 2013.

[27] X. Chen, M. A. Dam, K. Ono et al., "A thermally re-mendable cross-linked polymeric material,” Science, vol. 295, no. 5560, pp. 1698-1702, 2002.

[28] B. B. J. Adzima, C. J. Kloxin, and C. N. Bowman, "Externally triggered healing of a thermoreversible covalent network via self-limited hysteresis heating," Advanced Materials, vol. 22, no. 25, pp. 2784-2787, 2010.

[29] S. Y. Kwak, J. P. Giraldo, T. T. S. Lew et al., "Polymethacrylamide and carbon composites that grow, strengthen, and selfrepair using ambient carbon dioxide fixation," Advanced Materials, vol. 30, no. 46, p. 1804037, 2018.

[30] B. Ghosh and M. W. Urban, "Self-repairing oxetanesubstituted chitosan polyurethane networks," Science, vol. 323, no. 5920, pp. 1458-1460, 2009.

[31] Y. Amamoto, H. Otsuka, A. Takahara, and K. Matyjaszewski, "Self-healing of covalently cross-linked polymers by 
Reshuffling thiuram Disulfide moieties in air under visible light," Advanced Materials, vol. 24, no. 29, pp. 3975-3980, 2012.

[32] M. Capelot, D. Montarnal, F. Tournilhac, and L. Leibler, "Metal-catalyzed Transesterification for healing and assembling of thermosets," Journal of the American Chemical Society, vol. 134, no. 18, pp. 7664-7667, 2012.

[33] S. Utrera-Barrios, R. Verdejo, M. A. López-Manchado, and M. Hernández Santana, "Evolution of self-healing elastomers, from extrinsic to combined intrinsic mechanisms: a review," Materials Horizons, vol. 7, no. 11, pp. 2882-2902, 2020.

[34] J. J. Griebel, R. S. Glass, K. Char, and J. Pyun, "Polymerizations with elemental sulfur: A novel route to high sulfur content polymers for sustainability, energy and defense," Progress in Polymer Science, vol. 58, pp. 90-125, 2016.

[35] https://scholar.google.com/scholar?hl=en\&as_ sdt $=0 \% 2 \mathrm{C} 5 \& \mathrm{q}=$ self-healing+polymer\&btnG $=$.

[36] V. M. Vučurović, R. N. Razmovski, U. D. Miljić, and V. S. Puškaš, "Removal of cationic and anionic azo dyes from aqueous solutions by adsorption on maize stem tissue," Journal of the Taiwan Institute of Chemical Engineers, vol. 45, no. 4, pp. 1700-1708, 2014.

[37] Y. M. Malinskii, V. V. Prokopenko, N. A. Ivanova, and V. A. Kargin, "Investigation of self-healing of cracks in polymers," Polymer Mechanics, vol. 6, no. 2, pp. 240-244, 1973.

[38] A. M. Fainleib and O. H. Purikova, "Self-healing polymers: approaches of healing and their application," Polymer Journal, vol. 41, no. 1, pp. 4-18, 2019.

[39] A. K. Padhan and D. Mandal, Self-healing polymeric systems, INC, 2020.

[40] S. J. Garcia and H. R. Fischer, Self-healing polymer systems: properties, synthesis and applicationsWoodhead Publishing Limited.

[41] K. Guo, D. L. Zhang, X. M. Zhang et al., "Conductive elastomers with autonomic self-healing properties," Angewandte Chemie International Edition, vol. 54, no. 41, pp. 1212712133, 2015.

[42] J. A. Siddique, A. Ahmad, and A. Mohd, "Self healing materials and conductivity," in Electrically Conductive Polymer and Polymer Composites: From Synthesis to Biomedical Applications, pp. 163-180, 2018.

[43] J. F. Feller, I. Linossier, and Y. Grohens, "Conductive polymer composites: comparative study of poly(ester)-short carbon fibres and poly(epoxy)-short carbon fibres mechanical and electrical properties," Materials Letters, vol. 57, no. 1, pp. 6471, 2002.

[44] A. Khan, M. Jawaid, A. A. P. Khan, and A. M. Asiri, Electrically Conductive Polymer and Polymer Composites: From Synthesis to Biomedical Applications.

[45] S. Wang, J. Lei, X. Yi et al., "Fabrication of polypyrrole-grafted Gelatin-Based hydrogel with Conductive, Self-Healing, and injectable properties," ACS Applied Polymer Materials, vol. 2, no. 7, pp. 3016-3023, 2020.

[46] K. Wang, Z. Zhou, J. Zhang et al., "Electrical and thermal and self-healing properties of graphene-thermopolyurethane flexible conductive films," Nanomaterials, vol. 10, no. 4, p. 753, 2020.

[47] H. Yu, Y. Feng, L. Gao, C. Chen, Z. Zhang, and W. Feng, "Selfhealing high strength and thermal conductivity of 3D graphene/PDMS composites by the optimization of multiple molecular interactions," Macromolecules, vol. 53, no. 16, pp. 71617170, 2020.
[48] X. Wu, R. Luo, Z. Li, J. Wang, and S. Yang, "Readily selfhealing polymers at subzero temperature enabled by dual cooperative crosslink strategy for smart paint," Chemical Engineering Journal, vol. 398, p. 125593, 2020.

[49] A. Yabuki, S. Tanabe, and I. W. Fathona, "Self-healing polymer coating with the microfibers of superabsorbent polymers provides corrosion inhibition in carbon steel," Surface and Coating Technology, vol. 341, pp. 71-77, 2018.

[50] F. Ubaid, A. B. Radwan, N. Naeem et al., "Multifunctional selfhealing polymeric nanocomposite coatings for corrosion inhibition of steel," Surface and Coating Technology, vol. 372, pp. 121-133, 2019.

[51] N. Pirhady Tavandashti, M. Ghorbani, A. Shojaei, Y. Gonzalez-Garcia, H. Terryn, and J. M. C. Mol, "pH responsive Ce(III) loaded polyaniline nanofibers for self-healing corrosion protection of AA2024-T3," Progress in Organic Coatings, vol. 99, pp. 197-209, 2016.

[52] J. Wang, Q. Zhou, J. P. Wang, S. Yang, and G. L. Li, "Hydrophobic self-healing polymer coatings from carboxylic acidand fluorine- containing polymer nanocontainers," Colloids and Surfaces A: Physicochemical and Engineering Aspects, vol. 569, pp. 52-58, 2019.

[53] Y. Fu, F. Xu, D. Weng, X. Li, Y. Li, and J. Sun, "Superhydrophobic foams with chemical- and mechanical-damagehealing abilities enabled by self-healing polymers," ACS Applied Materials \& Interfaces, vol. 11, no. 40, pp. 3728537294, 2019.

[54] R. Zhao, Y. Chen, G. Liu, Y. Jiang, and K. Chen, "Fabrication of self-healing waterbased superhydrophobic coatings from POSS modified silica nanoparticles," Materials Letters, vol. 229, pp. 281-285, 2018.

[55] H. W. Kua, S. Gupta, A. N. Aday, and W. V. Srubar III, "Biochar-immobilized bacteria and superabsorbent polymers enable self-healing of fiber-reinforced concrete after multiple damage cycles," Cement and Concrete Composites, vol. 100, pp. 35-52, 2019.

[56] S. Gwon, E. Ahn, and M. Shin, "Water permeability and rapid self-healing of sustainable sulfur composites using superabsorbent polymer and binary cement," Construction and Building Materials, vol. 265, p. 120306, 2020.

[57] P. K. Koech, C. A. Fernandez, K. A. Rod et al., "Advanced selfhealing polymer-cement composites for geothermal wellbore application at $300{ }^{\circ} \mathrm{C}$," 2020, https://www.osti.gov/biblio/ 1644263.

[58] C. Zhang, X. Wang, D. Liang et al., "Rapid self-healing, multiple recyclability and mechanically robust plant oil-based epoxy resins enabled by incorporating tri-dynamic covalent bonding," Journal of Materials Chemistry A, vol. 9, no. 34, pp. 18431-18439, 2021.

[59] X. Qi, D. Zhang, Z. Ma et al., "An epidermis-like hierarchical smart coating with a hardness of tooth enamel," ACS Nano, vol. 12, no. 2, pp. 1062-1073, 2018.

[60] K. Ren, Y. Cheng, C. Huang, R. Chen, Z. Wang, and J. Wei, "Self-healing conductive hydrogels based on alginate, gelatin and polypyrrole serve as a repairable circuit and a mechanical sensor," Journal of Materials Chemistry C, vol. 7, no. 37, pp. 5704-5712, 2019.

[61] M. Tsai, T. L. Shen, H. M. Wu et al., "Self-Powered, SelfHealed, and shape-adaptive ultraviolet photodetectors," ACS Applied Materials \& Interfaces, vol. 12, no. 8, pp. 9755-9765, 2020. 
[62] M. Khatib, O. Zohar, W. Saliba, S. Srebnik, and H. Haick, "Highly efficient and water-insensitive self-healing elastomer for wet and underwater electronics," Advanced Functional Materials, vol. 30, no. 22, p. 1910196, 2020.

[63] M. Khatib, O. Zohar, W. Saliba, and H. Haick, "A multifunctional electronic skin empowered with damage mapping and autonomic acceleration of self-healing in designated locations," Advanced Materials, vol. 32, no. 17, p. 2000246, 2020.

[64] F. Li, S. Jiao, Z. Sun et al., "Self-repairing microcapsules with aqueous solutions as core materials for conductive applications," Green Chemistry, vol. 23, no. 2, pp. 927-934, 2021.

[65] S. S. Lee, H. D. Kim, S. H. L. Kim et al., "Self-healing and adhesive artificial tissue implant for voice recovery," ACS Applied Bio Materials, vol. 1, no. 4, pp. 1134-1146, 2018.

[66] L. Yang, Y. Zeng, H. Wu, C. Zhou, and L. Tao, “An antioxidant self-healing hydrogel for 3D cell cultures," Journal of Materials Chemistry B, vol. 8, no. 7, pp. 1383-1388, 2020.

[67] M. Tavakolizadeh, A. Pourjavadi, M. Ansari et al., "An environmentally friendly wound dressing based on a self-healing, extensible and compressible antibacterial hydrogel," Green Chemistry, vol. 23, no. 3, pp. 1312-1329, 2021.

[68] S. Fu, H. Zhou, H. Wang et al., "Amphibious superamphiphilic fabrics with self-healing underwater superoleophilicity," Materials Horizons, vol. 6, no. 1, pp. 122-129, 2019.

[69] E. Irzmańska, A. Bacciarelli-Ulacha, A. Adamus-Włodarczyk, and A. Strąkowska, "The effects of textile reinforcements on the protective properties of self-healing polymers intended for safety gloves," Textile Research Journal, vol. 90, no. 17-18, pp. 1974-1986, 2020.

[70] L. Chen, K. Guo, S. L. Zeng et al., "Cross-stacking aligned nonwoven fabrics with automatic self-healing properties for electromagnetic interference shielding," Carbon, vol. 162, pp. 445-454, 2020.

[71] M. Raimondo, L. Guadagno, V. Speranza, L. Bonnaud, P. Dubois, and K. Lafdi, "Multifunctional graphene/POSS epoxy resin tailored for aircraft lightning strike protection," Composites: Part B, vol. 140, pp. 44-56, 2018.

[72] Y. Zhu, K. Cao, M. Chen, and L. Wu, "Synthesis of UVresponsive self-healing microcapsules and their potential application in aerospace coatings," ACS Applied Materials \& Interfaces, vol. 11, no. 36, pp. 33314-33322, 2019.

[73] J. V. Nardeli, C. S. Fugivara, M. Taryba, M. F. Montemor, and A. V. Benedetti, "Biobased self-healing polyurethane coating with $\mathrm{Zn}$ micro-flakes for corrosion protection of AA7475," Chemical Engineering Journal, vol. 404, p. 126478, 2021.

[74] J. Araujo-Morera, M. Hernández Santana, R. Verdejo, and M. A. López-Manchado, "Giving a second opportunity to tire Waste: an alternative path for the development of sustainable self-healing Styrene-Butadiene rubber compounds overcoming the magic triangle of tires," Polymers, vol. 11, no. 12, p. 2122, 2019.

[75] Y. Yanagisawa, Y. Nan, K. Okuro, and T. Aida, "Mechanically robust, readily repairable polymers via tailored noncovalent cross-linking," Science, vol. 359, no. 6371, pp. 72-76, 2018.

[76] "End of the smashed phone screen? Self-healing glass discovered by accident," in Research and developmentThe GuardianAugust 2021, https://www.theguardian.com/technology/ 2017/dec/18/smashed-cracked-phone-screen-self-healingglass-university-of-tokyo.
[77] K. Yu, A. Xin, H. du, Y. Li, and Q. Wang, "Additive manufacturing of self-healing elastomers," NPG Asia Materials, vol. 11, no. 1, 2019.

[78] W. Ma, Y. Ding, Y. Li et al., "Durable, self-healing superhydrophobic nanofibrous membrane with self-cleaning ability for highly-efficient oily wastewater purification," Journal of Membrane Science, vol. 634, p. 119402, 2021.

[79] P. Wu, H. Cheng, X. Wang et al., "A self-healing and recyclable polyurethane-urea Diels-Alder adduct synthesized from carbon dioxide and furfuryl amine," Green Chemistry, vol. 23, no. 1, pp. 552-560, 2021.

[80] "Current applications of self-healing materials | Soft Robotics Toolkit," https://softroboticstoolkit.com/book/currentapplications-self-healing-materials.

[81] "Self-healing materials market size \& share report, 2019-2025," https://www.grandviewresearch.com/industry-analysis/selfhealing-materials.

[82] "The car of the future is electric and self-healing - MaterialDistrict," https://materialdistrict.com/article/car-future-electricself-healing/.

[83] "Versatile new material family could build realistic prosthetics, futuristic army platformsTexas A\&M University Engineeringhttps://engineering.tamu.edu/news/2020/08/ versatile-new-material-family-could-build-realisticprosthetics-futuristic-army-platforms.html.

[84] "3D printed self-healing polymers for more realistic prostheticsdesignnews.comhttps://www.designnews.com/materials/ 3d-printed-self-healing-polymers-more-realistic-prosthetics.

[85] A. M. Rodríguez-Alloza, M. Heihsel, J. Fry et al., "Consequences of long-term infrastructure decisions-the case of self-healing roads and their $\mathrm{CO}_{2}$ emissions," Environmental Research Letters, vol. 14, no. 11, p. 114040, 2019.

[86] J. Xie, M. Yang, J. Liang, J. Hu, Q. Li, and J. He, "Self-healing of internal damage in mechanically robust polymers utilizing a reversibly convertible molecular network," Journal of Materials Chemistry A, vol. 9, no. 29, pp. 15975-15984, 2021. 